\title{
Foreign Body Syndrome in Cattle: An Incidence and Clinico-Haemato-Biochemical Changes
}

\author{
A. S. Lakhpati*, B. N. Ambore, G. D. Wankhede, V. R. Patodkar, \\ S. U. Digraskar, R. V. Suryawanshi and A. B Mali \\ Department of Veterinary Clinical Medicine, Ethics and Jurisprudence, India \\ Krantisinh Nana Patil College of Veterinary Science, MAFSU, Shirwal, \\ Dist. Satara (MS), India \\ *Corresponding author
}

\begin{tabular}{|l|}
\hline K e y w o r d s \\
Areca nut, UHPLC, \\
Redox titration, \\
$\begin{array}{l}\text { Vitamin } \mathrm{B}_{6}, \\
\text { Vitamin C }\end{array}$ \\
\hline Article Info \\
\hline $\begin{array}{l}\text { Accepted: } \\
\text { 12 August } 2019 \\
\text { Available Online: } \\
\text { 10 September } 2019\end{array}$ \\
\hline
\end{tabular}

\section{A B S T R A C T}

The present research work was aimed to study an incidence, clinical findings and haemato-biochemical changes in foreign body syndrome in cattle. Overall incidence of FBS was $49.31 \%$ with highest in Holsten Friesian $(69.44 \%)$ followed by Jersey (8.33\%), Gir $(5.55 \%)$ and Non-descript $(5.55 \%)$. Further it was more in females $(91.66 \%)$ than male $(8.33 \%)$.General observations in FBS cases revealed change in posture and gait, distended and impacted rumen, scanty or loose faeces, normal to emaciated and hide bound body condition. Most of the affected females were in their third trimester of pregnancy or recently parturited. There was significant $(p<0.01)$ decrease in milk yield with overall decrease of $40.17 \%$.Common clinical signs observed in FBS affected cases were in appetence, absence of rumination, recurrent bloat, brisket oedema, jugular pulsation, changes in heart sounds, dyspnoea, coughing, arched back, abducted elbows and intermittent pain symptoms. There was Nonsignificant changes in body temperature while significant $(\mathrm{p}<0.01)$ increase in heart rate and respiratory rate and decrease in ruminal motility recorded. Haematology showed lymphocytopenia with neutrophilia and increase in band neutrophils. There was hypoalbuminemia and hyperglobinamia $(p<0.05)$ with significant $(p<0.01)$ increase in AST, ALT, CPK and LDH $(\mathrm{p}<0.05)$ levels in FBS cattle.

\section{Introduction}

Cattle are indiscriminate feeders. They can't differentiate between metallic materials in feed and do not completely masticate the food before swallowing (Aiello et al., 2016).
Hence, they ingest sharp metallic objects like nails or wires. These foreign bodies get settled in the reticulum, due to its honey comb structure. The foreign bodies remain there and starts puncturing the reticulum causing a disease which is known as "Foreign body 
syndrome" which is also known as "Hardware Disease", "sharp foreign body syndrome" (SFBS) or "traumatic reticuloperitonitis" (TRP). Foreign body syndrome has been recorded in bovine specifically in developing countries due to lack of recycling industrial wastes (Vanitha et al., 2010) and due to improper waste management.

The disease is commonly reported when green chop, silage and hay are made from fields that have old rusting fences or baling wire or when the grazing pastures are in the areas where buildings have recently been constructed.

Malnutrition and unbalanced dietary habits can also lead to ingestion of materials other than normal food including wastes (Otsyina $e t$ $a l ., 2015)$ leading to foreign body syndrome.

The disease has economically a great impact as it causes severe reduction of milk and death of animals. The magnitude of loss to dairy industry can be assessed from the fact that this complex has been responsible for more than $15 \%$ of all the natural deaths in dairy and beef animals (Sharma et al., 2015). In India, it has a high prevalence ranging from $23 \%$ to $87 \%$ (Hussain et al., 2018).

Economic losses and the number of animals affected are so high that it has driven researchers to go deep in the diagnosis and treatment of this syndrome (Makhdoomi et $a l ., 2018)$. There is a great variability in clinical signs of foreign body syndrome. Therefore, it is a significant challenge to diagnose and manage FBS.

Definitive diagnosis is a necessary prerequisite to decide on the surgical intervention to be employed. It is a clinical demand to evolve strategies to diagnose and manage traumatic reticuloperitonitis at an early stage (Rajput et al., 2018). Haematobiology and biochemistry plays an important role in the diagnosis and to know the extent of damage due to foreign body syndrome.

\section{Materials and Methods}

The present study was carried out during February, 2019 to July, 2019 in Teaching Veterinary Clinical Complex, Krantisinh Nana Patil College of Veterinary Science, Shirwal, Dist. Satara, Ambulatory Clinics and various Animal Health Camps.

The animals showing signs of either impaction/ recurrent tympany/ brisket oedema/ jugular pulsation/ arched back/ anorexia/ intermittent pain symptoms/ abducted elbows were screened for FBS by radiography and from the positive animals blood and serum was collected and evaluated.

\section{Clinical examination}

Detailed history of the case, species of animal, breed of the animal, sex and age of the animal, physiological status of the animal (Lactating/ Pregnant/ Dry), change in milk yield, change in appetite (Normal/ Increased/ In appetence), history of any tympany, the consistency of faeces (Normal/ Constipated/ Loose), urine out-put (Normal/ Increased/ Decreased), etc was taken from the owner.

Thorough clinical examination of foreign body syndrome affected cases was carried out.

The general body condition of the animal, its posture and gait were noted. Clinical observations viz. body temperature, heart rate, respiratory rate and ruminal motility of foreign body syndrome and healthy control group animals were recorded. Auscultation of the cardiac and thoracic region was recorded by standard methods. 


\section{Haematological examination}

The haematological parameters such as

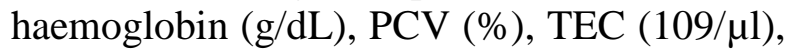
TLC $(103 / \mu \mathrm{l})$ and Differential Leucocyte Count including Neutrophils (\%), Band neutrophils (\%), Monocytes (\%), Eosinophils $(\%)$ and Basophils (\%) were estimated in the foreign body syndrome affected as well as healthy control group by using automated haemo-analyzer (Abacus junior vet 5, Diatron MI PLC, Hungary).

\section{Biochemical examination}

The obtained serum samples from the FBS affected and normal healthy animals were analysed for biochemical parameters by using standard diagnostic kits (M/s Pathozyme Diagnostics, Kolhapur). Total protein (g/dL) was estimated by modified biuret method, Albumin $(\mathrm{g} / \mathrm{dL})$ by modified BCG method and Globulin $(\mathrm{g} / \mathrm{dL})$ was estimated as the difference of albumin from total protein. AST (IU/L) and ALT (IU/L) were estimated by modified IFCC method, CPK (IU/L) and LDH (IU/L) by P-L, UV kinetic method on an autoanalyzer (Erba CHEM-7, Transasia biomedicals Ltd., India).

\section{Results and Discussion}

Total 73 cases presented showing signs of either impaction/ recurrent tympany/ brisket oedema/ jugular pulsation/ arched back/ anorexia/ intermittent pain symptoms/ abducted elbows were screened for FBS using radiography and the results were recorded.

\section{Incidence}

Out of 73 screened cases, 36 were positive for foreign body syndrome accounting $49.31 \%$ incidence. Breed-Wise incidence (Fig. 1) was found highest in Holsten Friesian 25 (69.44\%) followed by Jersey 3 (8.33\%), Gir 2 (5.55\%) and of non-descript cattle affected were 2
$(5.55 \%)$. The incidence in females was higher than in males. Out of 36 animals affected with Foreign Body Syndrome 33 (91.66\%) were female and $3(8.33 \%)$ were male. Hussain et al. (2018) also recorded prevalence of foreign Body Syndrome in cattle ranging from 23\% to $87 \%$. Sharma et al. (2015) found that of all the fore stomach disorders in cattle, $41.01 \%$ were of FBS including diaphragmatic hernia. $\mathrm{He}$ also recorded that the incidence in females $(94.73 \%)$ was more as compared to males (5.27\%) which correlates with the findings of the present study.

Present study also revealed that majority of the cases of cattle presented for forestomach disorders were due to foreign body syndrome, as cattle have an indiscriminate feeding habit (Singh et al.,2008). The incidence of FBS observed in females is much higher than in males, may be due to the fact that female population is more than the males as they are kept for milk production.

Also, high milk production may lead to calcium and phosphorus deficiency leading to pica and eating of inanimate objects (Ghurashi et al., 2009).

\section{Clinical signs}

General observations were noted in the foreign body syndrome cases, viz change in the posture and gait. Rumen was examined by inspection and palpation on the left flank region, consistency of the faeces, physiological status (pregnancy, lactation, dry), change in the milk yield were recorded. The results are depicted in Table.1.

\section{Change in the posture and gait}

Out of positive 36 cases for FBS, 11 animals (30.55\%) (Table 1) showed change in their posture and gait which included signs like arched back, holding the neck low, reluctance to move and sit, refusal to walk down a slope 
and staggering gait.

Such type of change in the posture and gait of FBS affected animals may be due to the presence of pain due to irritation of foreign body in the reticulum. The changes recorded in posture and gait in the present study are in accordance with the observations of Rajput $e t$ al. (2018).

\section{Rumen examination}

The rumen examination was carried out by inspection and palpation of the rumen from the left flank or by per rectal palpation of the rumen.

From the 36 positive cases for FBS, normal rumen was inspected in 14 cases $(38.88 \%)$, distended rumen in 14 cases $(38.88 \%)$ and on palpation impacted rumen was recorded in 8 cases $(22.22 \%)$ as shown in Table 1.

The present findings are corroborating with the findings of Braun et al. (2018) who also recorded normal rumen examination in 37\% cases of foreign body syndrome, tympany in $10 \%$ and $7 \%$ had firm rumen. Sasikala et al. (2018) found tympany in $33.63 \%$ FBS cases, which agrees to the findings in the present study. Singh et al. (2015) in their study found impacted rumen in 3 out of the 4 animals indicating $75 \%$ cases with impacted rumen which had foreign body syndrome.

The impaction observed in the FBS positive cases might be due to the reduced ruminal motility which is a result of adhesions of the reticulum, disturbances in the contractions which in turn causes decrease in the outflow and increase in the content of rumen and reticulum even in the conditions of low feed intake. In a study by Rajput et al. (2018) reported tympany in $90 \%$ cases of TRP while El esawy et al. (2015) found $18.9 \%$ cases of tympany due to traumatic reticuloperitonitis. The reason for tympany could be due to the consumption of large amount of indigestible material and alteration in the rumen-reticular motility leading to difficulty in the eructation. The tympany seen in the cases of diaphragmatic hernia because of foreign body is due to the adhesions of the reticulum which interferes with the ruminal peristalsis (Rajput et al., 2018; El esawy et al., 2015).

\section{Faecal consistency}

The faeces passed by the animals affected with foreign body syndrome were of variable consistency as depicted in Table1.

Out of 36 positive cases, 21 animals $(58.33 \%)$ were with normal faeces, 8 animals $(22.22 \%)$ were passing scanty faeces and 7 animals (19.44\%) were passing loose faeces. Similarly, Athar et al. (2010) also reported, scanty faeces in $22.22 \%$ of the animals, $11.11 \%$ were constipated and $11.11 \%$ had diarrhoea suffering from diffuse peritonitis correlating to the findings of the present study, whereas $16.67 \%$ animals with localized peritonitis had normal faeces. El esawyet al. (2015) observed $29.7 \%$ cases with diarrhoea and $32.4 \%$ cases had loose faeces in traumatic reticuloperitonitis. Sasikala et al. (2018) found scanty faeces in $83.63 \%$ cases of traumatic reticuloperitonitis, which is higher than the findings in the present study.

Abdelaal and Floeck (2015) also found that in the animals suffering from traumatic reticuloperitonitis had normal defecation in $16.66 \%$ animals, $77.77 \%$ were with scanty faeces and $5.55 \%$ had diarrhoea. In the cases of FBS, the composition and the consistency of the faeces becomes abnormal as there is increase in the transit time.

In some cases, there is retention of the ingesta as there is increase in the peristaltic movement of the intestines. The retention can also be as a result of increase in the dry matter content of the faeces (Guard, 2002). 
Table.1 General observations in FBS cases in cattle

\begin{tabular}{|c|c|c|c|c|c|c|c|}
\hline $\begin{array}{l}\text { Sr } \\
\text { No }\end{array}$ & \multicolumn{5}{|c|}{ Particulars } & Number & Percent \\
\hline 1 & \multicolumn{5}{|c|}{ Change in Posture and gait } & 11 & 30.55 \\
\hline \multirow[t]{3}{*}{2} & \multirow{3}{*}{\multicolumn{3}{|c|}{ Rumen examination }} & a & Normal & 14 & 38.88 \\
\hline & & & & $\mathrm{b}$ & Distended & 14 & 38.88 \\
\hline & & & & $\mathrm{c}$ & Impacted & 8 & 22.22 \\
\hline 3 & \multirow{3}{*}{\multicolumn{3}{|c|}{ Faeces }} & $\mathrm{b}$ & Normal & 21 & 58.33 \\
\hline & & & & $\mathrm{a}$ & Scanty & 8 & 22.22 \\
\hline & & & & $\mathrm{c}$ & Loose & 7 & 19.44 \\
\hline \multirow[t]{4}{*}{4} & \multirow{4}{*}{\multicolumn{3}{|c|}{ General body condition }} & $\mathrm{a}$ & Normal & 7 & 19.44 \\
\hline & & & & $\mathrm{b}$ & Lean (thin) & 6 & 16.66 \\
\hline & & & & $\mathrm{c}$ & Emaciated & 21 & 58.33 \\
\hline & & & & d & Hide bound & 2 & 05.55 \\
\hline \multirow[t]{5}{*}{5} & \multirow[t]{5}{*}{$\begin{array}{l}\text { Physiological } \\
\text { Status (n=33) }\end{array}$} & \multirow[t]{3}{*}{$\mathrm{a}$} & \multirow[t]{3}{*}{$\begin{array}{l}\text { Pregnant } \\
(n=15)\end{array}$} & 1 & $\begin{array}{l}\text { First trimester } \\
\text { (1-3 months) }\end{array}$ & 2 & 13.33 \\
\hline & & & & 2 & $\begin{array}{l}\text { Second } \\
\text { trimester } \\
(4-6 \text { months) }\end{array}$ & 4 & 26.66 \\
\hline & & & & 3 & $\begin{array}{l}\text { Third trimester } \\
\text { (7-9 months) }\end{array}$ & 9 & 60.00 \\
\hline & & $\mathrm{b}$ & \multicolumn{3}{|c|}{ Lactating (Early) } & 17 & 51.51 \\
\hline & & $\mathrm{c}$ & Dry & & & 1 & 03.03 \\
\hline \multirow[t]{2}{*}{6} & \multirow{2}{*}{\multicolumn{3}{|c|}{$\begin{array}{l}\text { Change in milk yield in lactating } \\
\text { animals }(\mathrm{n}=23)\end{array}$}} & $\mathrm{a}$ & Reduced & 21 & 91.30 \\
\hline & & & & $\mathrm{b}$ & Stopped & 2 & 08.69 \\
\hline
\end{tabular}

Table 2 Clinical observations in cattle affected with FBS

\begin{tabular}{|c|c|c|c|c|c|}
\hline Sr No & \multicolumn{3}{|c|}{ Particulars } & Number & Per cent \\
\hline 1 & \multicolumn{3}{|l|}{ Inappetence } & 34 & 94.44 \\
\hline \multirow[t]{3}{*}{2} & Rumination & $\mathrm{a}$ & Present & 9 & 25.00 \\
\hline & & $\mathrm{b}$ & Intermediate & 7 & 19.44 \\
\hline & & $\mathrm{c}$ & Absent & 20 & 55.55 \\
\hline 3 & \multicolumn{3}{|c|}{ Recurrent bloat } & 15 & 41.66 \\
\hline 4 & \multicolumn{3}{|c|}{ Brisket oedema } & 17 & 47.22 \\
\hline 5 & \multicolumn{3}{|c|}{ Jugular pulsation } & 22 & 61.11 \\
\hline 6 & \multicolumn{3}{|c|}{ Change in heart sound (Muffled \& Frictional) } & 28 & 77.77 \\
\hline 7 & \multicolumn{3}{|l|}{ Dyspnoea } & 25 & 69.44 \\
\hline 8 & \multicolumn{3}{|l|}{ Coughing } & 22 & 61.11 \\
\hline 9 & \multicolumn{3}{|l|}{ Arched back } & 9 & 25.00 \\
\hline 10 & \multicolumn{3}{|c|}{ Abducted elbows } & 13 & 36.11 \\
\hline 11 & \multicolumn{3}{|c|}{ Intermittent pain symptoms } & 30 & 83.33 \\
\hline
\end{tabular}


Table.3 Clinical parameters in FBS and healthy control cattle

\begin{tabular}{|c|c|c|}
\hline Parameters & FBS cases & Healthy Control \\
\hline Temperature $\left({ }^{\mathbf{0}} \mathbf{F}\right)$ & $101.99 \pm 0.26$ & $101.07 \pm 0.31$ \\
\hline $\begin{array}{c}\text { Heart Rate } \\
\text { (beats per minute) }\end{array}$ & $80.64 \pm 2.74^{* *}$ & $45.60 \pm 2.90$ \\
\hline $\begin{array}{c}\text { Respiratory Rate } \\
\text { (breadths per minute) } \\
\begin{array}{c}\text { Rumen Motility } \\
\text { (per 5 minute) }\end{array}\end{array}$ & $39.14 \pm 2.68^{* *}$ & $20.60 \pm 1.11$ \\
\hline$* *(\mathrm{p}<0.01)$ & $0.86 \pm 0.21^{* *}$ & $2.20 \pm 0.13$ \\
\hline
\end{tabular}

Table.4 Haematological values (Mean \pm SE) in FBS and healthycontrol.

\begin{tabular}{|c|c|c|}
\hline Parameters & Positive cases of FBS & Healthy Control \\
\hline Haemoglobin (g/d) & $9.75 \pm 0.44$ & $10.82 \pm 0.52$ \\
\hline PCV $(\mathbf{\%})$ & $29.71 \pm 1.45$ & $34.36 \pm 1.64$ \\
\hline TEC $(\mathbf{1 0} / \boldsymbol{\mu l})$ & $6.30 \pm 039$ & $6.95 \pm 0.36$ \\
\hline TLC $(\mathbf{1 0} / \boldsymbol{\mu l})$ & $12.48 \pm 1.00$ & $9.43 \pm 0.49$ \\
\hline Neutrophils $(\%)$ & $52.08 \pm 2.23^{* *}$ & $27.70 \pm 3.94$ \\
\hline Band neutrophils (\%) & $3.12 \pm 0.76^{*}$ & $0.30 \pm 0.21$ \\
\hline Lymphocytes (\%) & $42.80 \pm 2.84^{* *}$ & $69.60 \pm 2.57$ \\
\hline Monocytes (\%) & $1.08 \pm 0.22$ & $1.00 \pm 0.21$ \\
\hline Eosinophils (\%) & $1.64 \pm 0.34$ & $0.50 \pm 0.34$ \\
\hline Basophils $(\%)$ & $0.08 \pm 0.06$ & $0.00 \pm 0.00$ \\
\hline
\end{tabular}

Table.5 Biochemical values (Mean \pm SE) in FBS and healthy control

\begin{tabular}{|c|c|c|}
\hline Parameters & FBS positive cases & Healthy Control \\
\hline Total protein (g/dl) & $6.87 \pm 0.15$ & $6.71 \pm 0.18$ \\
\hline Albumin (g/dl) & $2.91 \pm 0.21$ & $3.58 \pm 0.18$ \\
\hline Globulin (g/dl) & $3.96 \pm 0.22^{*}$ & $3.13 \pm 0.13$ \\
\hline SGPT/ALT (IU/L) & $71.27 \pm 8.51^{* *}$ & $28.82 \pm 5.05$ \\
\hline SGOT/AST (IU/L) & $117.41 \pm 14.07^{* *}$ & $37.02 \pm 6.61$ \\
\hline CPK (IU/L) & $163.62 \pm 19.89^{* *}$ & $71.12 \pm 2.22$ \\
\hline LDH (IU/L) & $519.98 \pm 27.51^{*}$ & $318.20 \pm 67.04$ \\
\hline
\end{tabular}

$*(\mathrm{p}<0.05) ; * *(\mathrm{p}<0.01)$ 
Fig.1 Breed-wise incidence of foreign body syndrome in cattle.

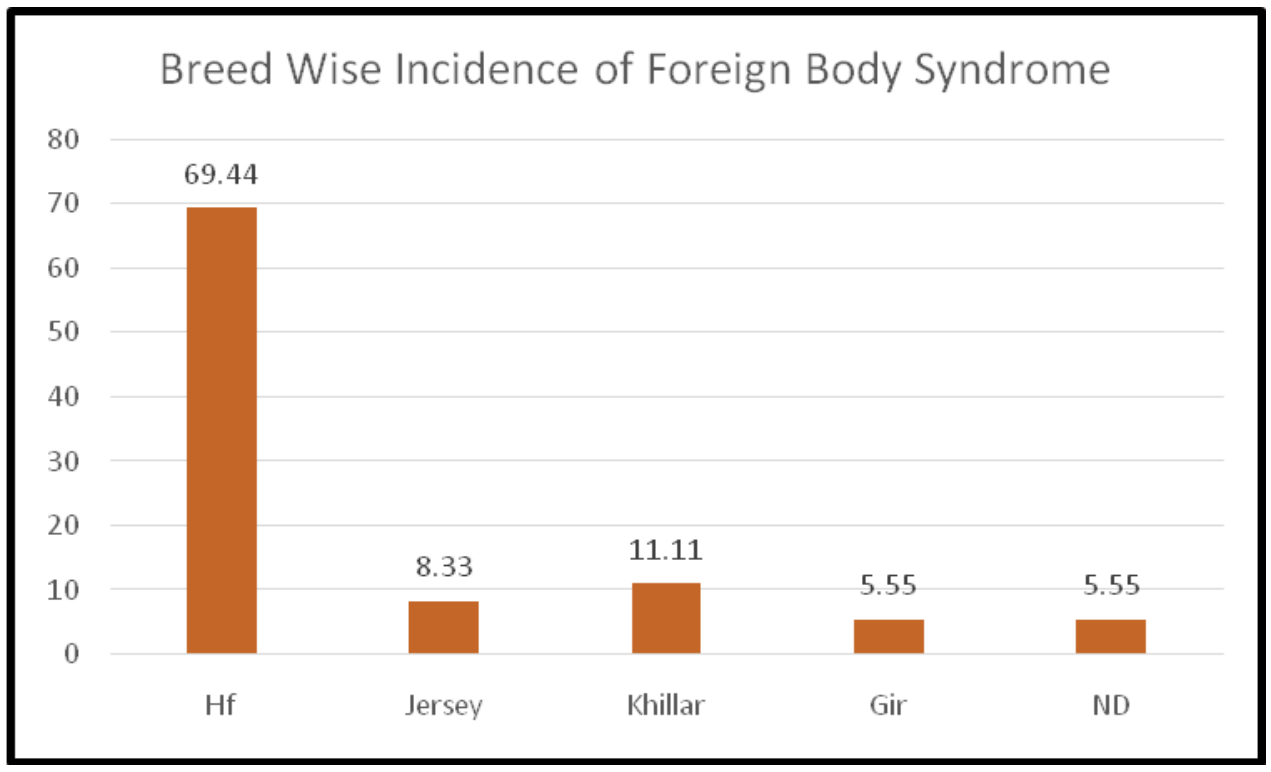

Fig.2 Milk yield (litres) before and during illness in FBS affected cattle.

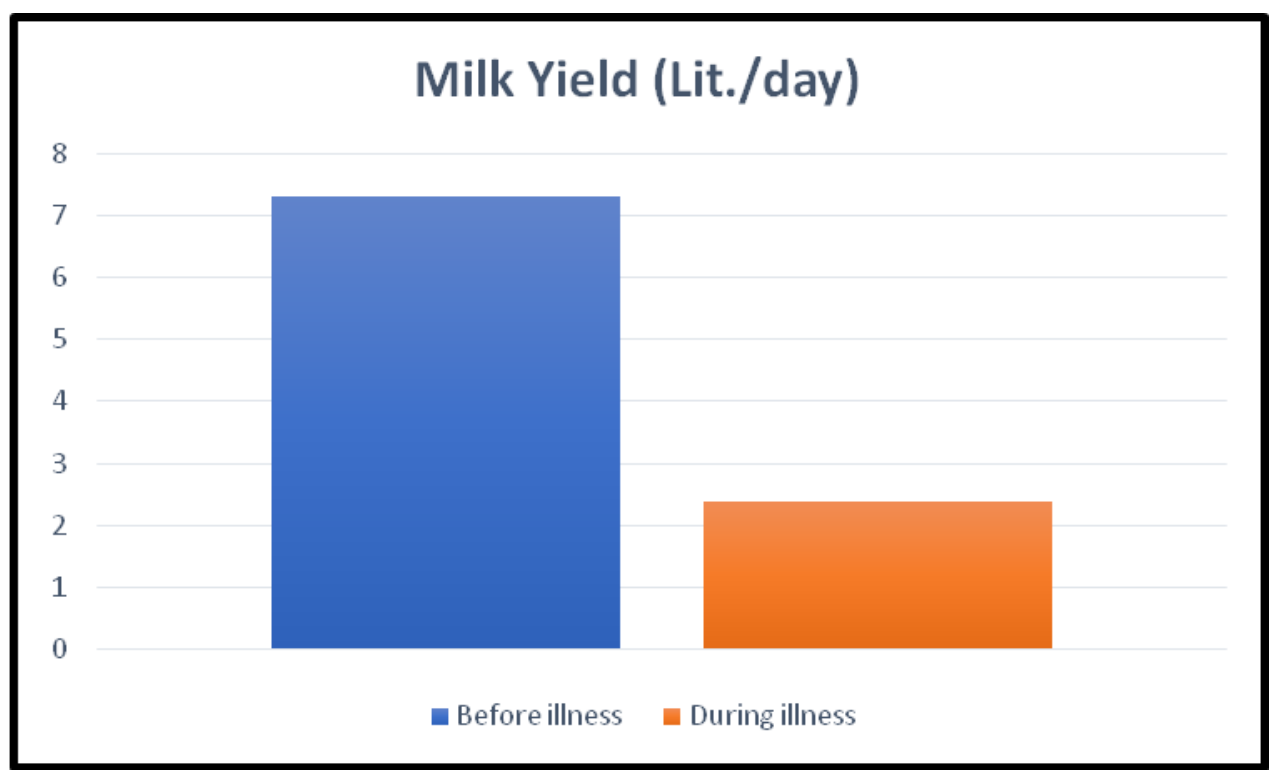


Fig.3 Clinical parameters in FBS affected and healthy control cattle

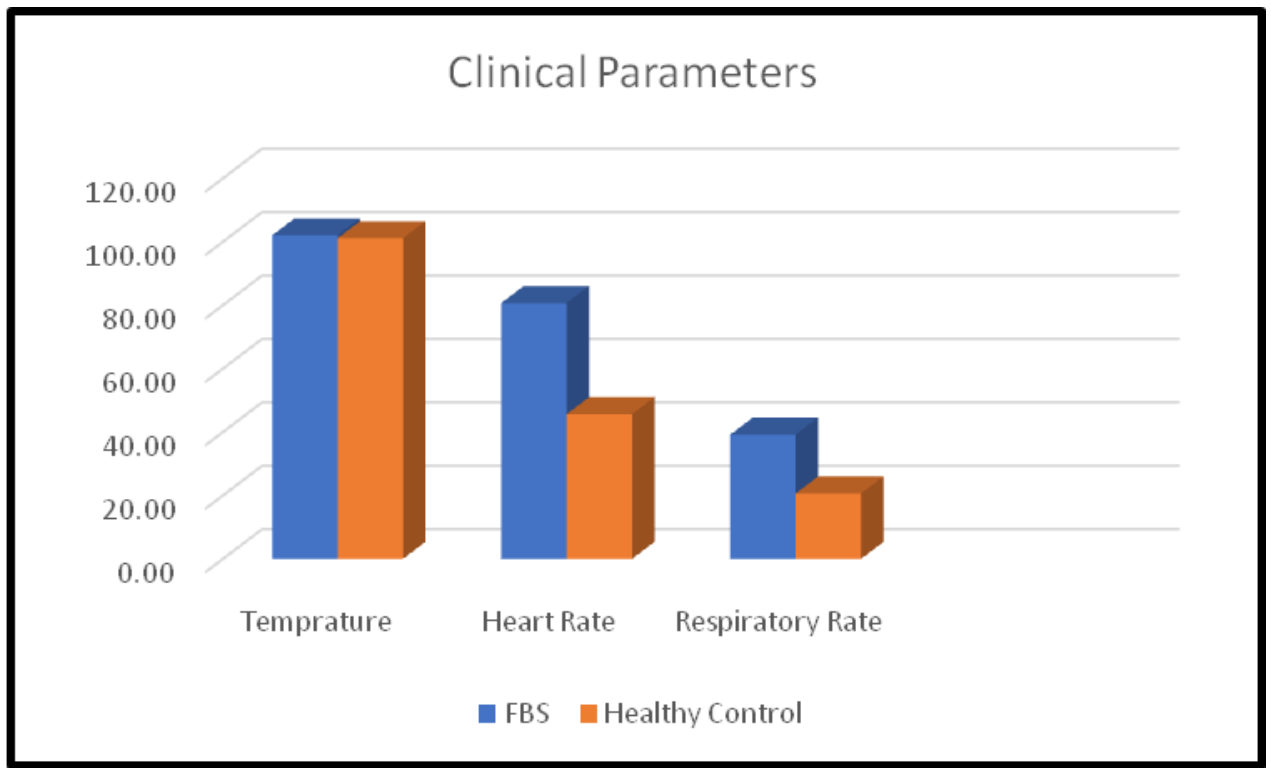

Fig.4. Rumen motility (per 5 minutes) in FBS and healthy cattle.

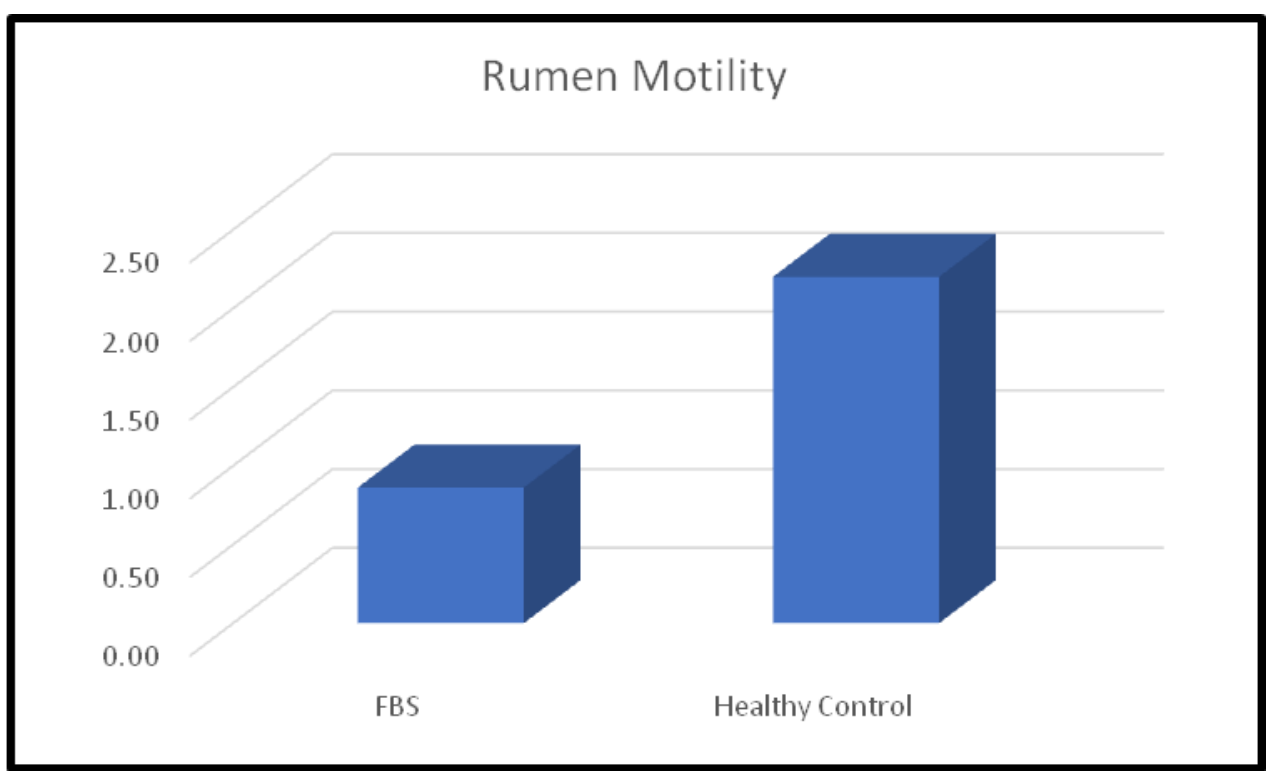


Fig. 5. Serum biochemical values in FBS and healthy control animals.

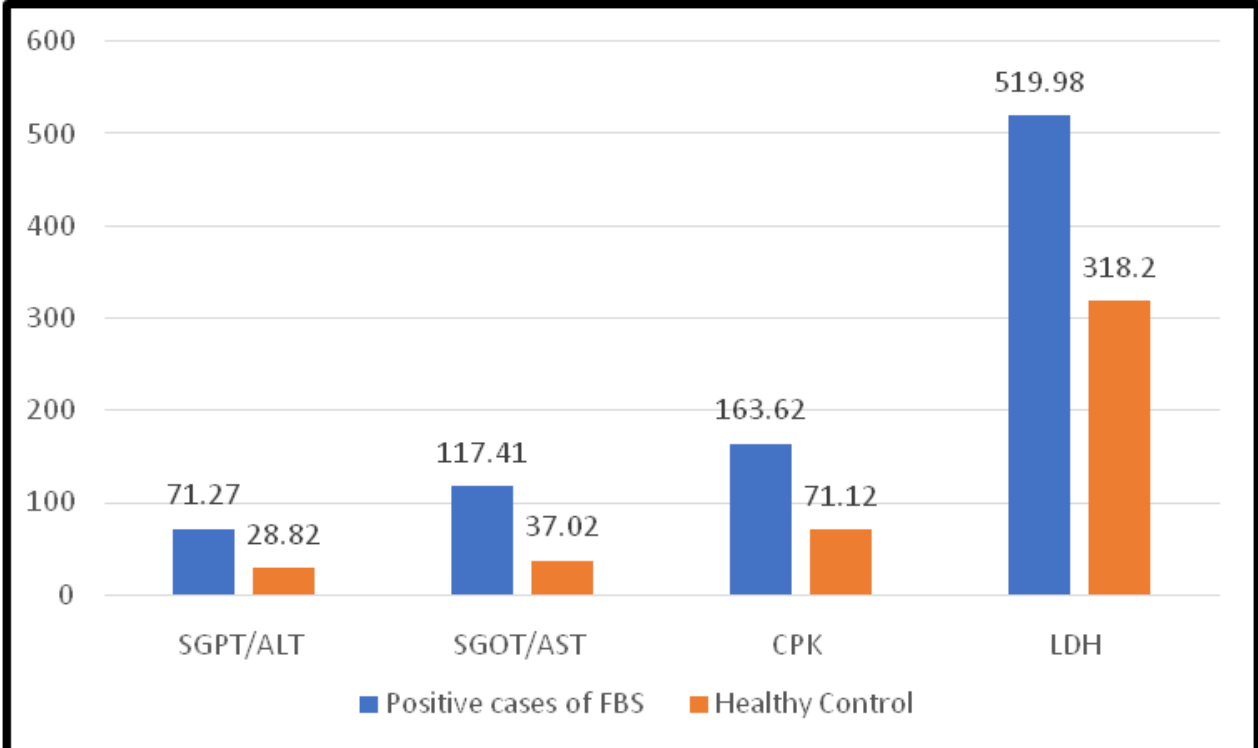

\section{General body condition}

The body condition of the animals positive for FBS varied greatly. Of the 36 positive cases, normal body condition was seen in 7 $(19.44 \%), 6(16.66 \%)$ animals were lean or thin, $21(58.33 \%)$ were emaciated and 2 (5.55\%) animals were hide bound body condition as shown in Table 1.El esawy et al. (2015) also reported $43.2 \%$ animals with emaciated body condition in traumatic reticulo-peritonitis which is similar to the finding in the present study. In another study carried out by Khalphallah et al. (2017) found $62.96 \%$ animals with emaciated body condition in foreign body syndrome. Braun et al. (2018) also reported similar findings in FBS as $13 \%$ animals were with normal body condition, $84 \%$ were mild to moderate deterioration and $3 \%$ were markedly abnormal body condition. All these findings support the findings in present study. The reason for emaciated and poor body condition, in most of the affected animals, could be that the foreign bodies interfere with the absorption of volatile fatty acids in the rumen leading to inappetence, abdominal distension, reduction in weight gain and lack of defecation leading to emaciation (Igbokwe et al., 2003; Abdelaal and El- Maghawry, 2014).

\section{Physiological status}

Among the 36 positive cases in the present study 33 were females of which $15(45.45 \%)$ were pregnant. The animals in the first trimester of pregnancy were $2(13.33 \%)$, in the second trimester $4(26.66 \%)$ and in the third trimester were $9(60 \%)$. The animals recently parturited and in their early lactation were $17(51.51 \%)$ and one animal was dry $(3.03 \%)$ as shown in Table 1.Similar findings were noticed by Mohamed $\mathrm{T}$ (2010) in traumatic pericarditis where they found $85 \%$ of the affected animals were pregnant of which $30 \%$ were in the first trimester $12.5 \%$ were in the second and $42.5 \%$ were in the third trimester. Nasr-Eldin and Abdel-Hakiem (2013) in their study found that $47.72 \%$ cases, affected by foreign body syndrome, were pregnant. which is similar to the present 
study. Rajput et al. (2018) found $45 \%$ recently calved and $30 \%$ pregnant animals were affected by foreign body syndrome which is in accordance with the present study. FBS is mostly seen in the periparturient period as there is an increase in the intraabdominal pressure due to pregnancy and parturition (Rajput et al.,2018). This attribute to penetration of the foreign body and the exhibition of the clinical signs. Hence, majority of the cases seen are in the mid to late pregnancy or have recently parturited and are in early lactation.

\section{Effect on milk yield}

A total of 23 animals were lactating of the FBS affected animals. Drop in the milk yield was observed in $100 \%$ of the affected animals, of which there was reduction in milk yield found in $21(91.30 \%)$ animals and 2 animals $(8.69 \%)$ had completely stopped lactating (Table 1). The average milk yield before the disease was $7.30 \pm 0.53$ litres/day which was reduced to $2.39 \pm 0.27$ litres per day showing a significant $(\mathrm{p}<0.01)$ decrease in the milk yield with an overall decrease of $40.17 \%$ (Fig. 2).

There were number of studies carried out on the effect of foreign body syndrome on milk yield. Mohamed T (2010) found that $75 \%$ of the animals showed reduction in the milk production, whereas Abdelaal et al. (2009) found $100 \%$ of the affected animals shown decrease in the milk yield. Khalphallah et al. (2017) found that $100 \%$ of the animals suffering from traumatic reticulo-peritonitis had decrease in the milk production.

All these findings are in agreement with the findings in the present study. The animals affected by foreign body syndrome showing significant and sharp drop in the milk yield could be due to pain and reduction in the feed intake (Abu-Seida and Al-Abbadi, 2015).
This is one of the most important clinical finding in foreign body syndrome and encountered heavy economic losses during the course of disease.

\section{Clinical Observations}

The clinical observations recorded in the positive cases of foreign body syndrome are shown in Table.2.

It has been observed that 34 cases $(94.44 \%)$ showed inappetence. Rumination was normal and present in $9(25 \%)$ cases, while it was intermittent in $7(19.44 \%)$ and was completely absent in $20(55.55 \%)$ cases of FBS. Recurrent bloat was seen in 15 (41.66\%) animals, brisket oedema was in $17(47.22 \%)$ while jugular pulsation was observed in 22 cases $(61.11 \%)$. Change in heart sound was observed in $28(77.77 \%)$ animals, in most of the cases the heart sound was muffled and it was frictional in the long-standing FBS cases and in cases positive for diaphragmatic hernia. Dyspnoea and coughing were seen in $25(69.44 \%)$ and 22 cases (61.11\%), respectively.

Arched back and abducted elbows were seen in $9(25 \%)$ and 13 cases (36.11\%), respectively. Intermittent pain symptoms like reluctance to move, long standing posture, stiffness and stretching position were seen in $30(83.33 \%)$ cases. Earlier, Abdelaal et al. (2009) reported inappetence in $100 \%$ cases of traumatic reticulo-peritonitis affected animals while pain symptoms were seen in $93.10 \%$ of the animals. El esawy et al. (2015) also observed inappetence in $100 \%$ animals affected with FBS.

They found muffled heart sound in $13.5 \%$ cases, dyspnoea in $21.6 \%$, coughing in $18.9 \%$, brisket oedema was in $13.5 \%$ and jugular vein distension was seen in $13.5 \%$ of the cases, these findings are in accordance with the 
present findings. Further, Roth and King (1991) recorded muffled heart sounds in 65\% cases with traumatic reticulitis. Abouelnasr et al. (2012) found reduced appetite in $100 \%$ cases, recurrent bloat in $87.5 \%$ in the cases with traumatic reticulo-peritonitis. In FBS affected cases there was anorexia in $92.72 \%$ cases and recurrent bloat in $33.63 \%$ cases (Sasikala et al., 2018). Rajput et al. (2018) also observed suspended rumination in $75 \%$ cases and decreased rumination in $25 \%$ animals affected with foreign body syndrome. All these earlier findings in FBS affected animals are in support with the findings of present investigation.

The most common signs observed in the FBS affected animals were inappetence, reduction or suspension in rumination and change in the heart sounds. These changes can be attributed to ruminal impaction due to the alterations caused in rumen-reticular motility, due to foreign body in rumen or reticulum. Recurrent bloat is a common sign seen in the cases of diaphragmatic hernia, as there is hindrance in the eructation (Rajput et al., 2018) and motility because of the herniation of the reticulum in the thorax.

Brisket oedema, jugular pulsation, coughing and dyspnoea are the signs of involvement of the cardiovascular system (Ghanem, 2010). Dyspnoea is also commonly seen when the rumen is distended as it exerts pressure on the diaphragm.

The signs of pain like arching of back, abduction of elbows, difficulty while lying down or getting up, reluctance to move may vary greatly in different cases, as it depends on the position of the metallic body penetration. These symptoms can also be exhibited because of impaction due to nonmetallic foreign body which also exerts pressure on the vital organs (Rajput et al., 2018).

\section{Clinical parameters}

The clinical parameters viz. temperature, heart rate, respiratory rate and ruminal motility were recorded in FBS affected cases and in 10 clinically healthy animals as control using standard methods and the results are given in Table.3.

The temperature recorded in the affected animals was $101.99 \pm 0.26{ }^{\circ} \mathrm{F}$ which was within the normal range and did not show significant difference from the healthy control $\left(101.07 \pm 0.31{ }^{\circ} \mathrm{F}\right)$. The mean heart rate in affected animals was $80.64 \pm 2.74$ beats per minute which was significantly higher $(\mathrm{p}<$ $0.01)$ than the healthy control group $(45.60 \pm$ 2.90 beats per minute). The mean respiratory rate in the FBS affected animals was $39.14 \pm$ 2.68 per minute which was significantly higher $(\mathrm{p}<0.01)$ than the healthy control (20.60 \pm 1.11 per minute) (Fig. 3). The rumen motility was recorded per 5 minutes (Fig.4), the mean ruminal motility in the affected cattle was $0.86 \pm 0.21$ which was significantly lower $(\mathrm{p}<0.01)$ than the healthy control $(2.20$ \pm 0.13 per 5 minutes). The present findings corroborate with the findings of earlier scientists as Athar et al. (2010) who recorded mean rectal temperature $(102.7 \pm 0.43 \mathrm{oF})$, heart rate $(66.55 \pm 3.46$ beats per minute) and respiratory rate $(28.89 \pm 1.44$ per minute $)$ in traumatic reticulo-peritonitis cases in bovines. Ghanem (2010) also found higher respiratory rate $(48.5 \pm 4.5$ per minute) in traumatic reticulo-peritonitis cases than normal animals. He also found decreased ruminal motility (1/2 minute) in TRP. Khalphallah et al. (2017) found elevated heart rate in traumatic pericarditis (TP) at its initial stage and decrease in the later stage in buffaloes.

A study was done on traumatic reticuloperitonitis in cattle by Peighambrazadeh and Tavana (2014) where they recorded mean 
rectal temperature as $102.38^{\circ} \mathrm{F}$, heart rate ranged between 42.80 to 86 beats per minute, the respiratory rate was between 33.58 to 39 per minute and the ruminal motility was reduced in all the cases. Singh et al. (2015) studied of foreign body syndrome cases and recorded mean rectal temperature as $99.99 \pm 0.40{ }^{\circ} \mathrm{F}$, heart rate $(72.75 \pm 6.52$ beats per minute) and the ruminal motility was $1 \pm$ 0.57 per 5 minutes. All these findings are in agreement with the present study. The mean temperature did not show alteration when compared to the healthy control, some cases with higher rectal temperature in the present study might be due to peritonitis and septicaemia which can be because of recent parturition and complications like metritis or mastitis (Braun et al, 2007). The increase in the respiratory rate could be due to increased pressure of the distended rumen on the diaphragm (Bakhiet, 2008). The increase in the heart rate could also be due to the migration of the foreign body towards the thorax. The ruminal movements are reduced and absent in some cases because of change in the motility, which is caused because of impaction or distension (Akraiem and AlGalil, 2016) or due to the pain which is elicited as the foreign body pierces in the reticular wall (Braun et al., 2018).

\section{Haematological examination}

The haematological study was carried in foreign body syndrome positive cases and 10 healthy control animals. The results are shown in Table 4.The cases positive for foreign body syndrome revealed nonsignificant change in mean haemoglobin $(9.75 \pm 0.44 \mathrm{~g} / \mathrm{dl})$ level as against healthy control group $(10.82 \pm 0.52 \mathrm{~g} / \mathrm{dl})$. The mean PCV in affected animals was $29.71 \pm 1.45 \%$ which also did not show any significant difference from the healthy control (34.36 \pm $1.64 \%)$. The mean total erythrocyte count also showed non-significant difference, as it was
$6.30 \pm 039 \times 109 / \mu 1$ in the affected cases as compared to $6.95 \pm 0.36 \mathrm{x} 109 / \mu \mathrm{l}$ in healthy control animals. There was marginal but nonsignificant increase in the leukocyte count $(12.48 \pm 1.00 \times 103 / \mu 1)$ in the affected animals as compared to the healthy control $(9.43 \pm 0.49 \times 103 / \mu 1)$. Highly significant increase $(\mathrm{p}<0.01)$ in the neutrophils $(52.08 \pm$ $2.23 \%$ ) was recorded in the FBS affected animals as against healthy control (27.70 \pm $3.94 \%)$. Also, there was a significant increase $(\mathrm{p}<0.05)$ in the band neutrophils $(3.12 \pm$ $0.76 \%$ ) in the affected animals than healthy control group $(0.30 \pm 0.21 \%)$. Lymphocyte count was significantly $(\mathrm{p}<0.01)$ lower $(42.80$ $\pm 2.84 \%)$ in the affected animals when compared to the healthy control (69.60 \pm $2.57 \%$ ). The eosinophils, basophils and the monocytes did not show any significant difference as compared to the healthy control animals. Khalphallah et al. (2017) found no change in the mean haemoglobin $(118 \pm 4.5$ $\mathrm{g} / \mathrm{L})$, erythrocyte count $(7.12 \pm 1.32 \times 106 / \mu \mathrm{l})$ and PCV $(25.81 \pm 2.6 \%)$ values, while there was leucocytosis $(12.50 \pm 2.51 \times 103 / \mu \mathrm{l})$ in traumatic pericarditis affected buffaloes as compared to the healthy control corroborating the findings of present study. Sasikala et al. (2018) were also reported no change in haemoglobin, erythrocyte count and the PCV values but found leucocytosis $(19.99 \pm 0.84 \mathrm{x}$ $103 / \mu \mathrm{l})$ and neutrophilia (15.81 $\pm 0.5 \mathrm{x}$ $103 / \mu 1$ ) in traumatic reticulo-peritonitis as compared to the healthy control.

These findings are also in accordance with the present findings. Further, similar findings were observed by Khalphallah et al. (2016) and Rajput et al. (2018) in foreign body syndrome cases.

The findings of the haematological study revealed that all the animals were out of risk of anaemia as the haemoglobin concentration, total erythrocytecount and the PCV were in the normal range. There was leucocytosis 
which may indicate presence of localized infection or inflammatory status of the animal. The presence of neutrophilia with lymphopenia could be due to the presence of the foreign body in the forestomach leading to tissue injury or purulent exudation (Rajput et al., 2018). The leukocyte number will vary in between the species and reflects the balance of production, release and consumption from the bone marrow (Weiser et al., 2012). Cattle has low regenerative capacity and relatively low reserve and hence to sustain the neutrophilia in inflammation or infection an increased number of band cells are seen, especially in chronic state of the disease condition.

\section{Biochemical examination}

The positive cases for foreign body syndrome and healthy control animals were evaluated for biochemical parameters viz. total protein, albumin, globulin, ALT, AST, CPK and LDH by using standard kits. The results are depicted in Table 5 and Fig. 5.There was nonsignificant increase in serum protein $(6.87 \pm$ $0.15 \mathrm{~g} / \mathrm{dl})$ decrease in albumin $(2.91 \pm$ $0.21 \mathrm{~g} / \mathrm{dl})$ in FBS affected animals as compared to the healthy control (6.71 \pm $0.18 \mathrm{~g} / \mathrm{dl}$ and $3.58 \pm 0.18 \mathrm{~g} / \mathrm{dl}$, respectively) animals while there was significant $(\mathrm{p}<0.05)$ increase in serum globulin $(3.96 \pm 0.22 \mathrm{~g} / \mathrm{dl})$ level in the affected animals as compared to the healthy control $(3.13 \pm 0.13 \mathrm{~g} / \mathrm{dl})$. Also there was a significant increase $(p<0.01)$ in the mean values of AST $(117.41 \pm 14.07 \mathrm{IU} / \mathrm{L})$ and ALT $(71.27 \pm 8.51 \mathrm{IU} / \mathrm{L})$ in FBS cases as compared to healthy control $(37.02 \pm 6.61$ IU/L and $28.82 \pm 5.05 \mathrm{IU} / \mathrm{L}$, respectively). Increase in the values of CPK $(163.62 \pm 19.89$ IU/L) were highly significant $(\mathrm{p}<0.01)$ as compared to healthy control $(71.12 \pm 2.22$ IU/L) while LDH $(519.98 \pm 27.51 \mathrm{IU} / \mathrm{L})$ level was significantly increased $(\mathrm{p}<0.05)$ in FBS affected cattle as against healthy (318.20 \pm $67.04 \mathrm{IU} / \mathrm{L})$.
Similar findings were also recorded by Ghanem (2010) reported significant increase in the values of AST (TRP: $65.5 \pm 4.6 \mathrm{IU} / \mathrm{L}$; TP: $312 \pm 15.5 \mathrm{IU} / \mathrm{L}$ ), ALT (TRP: $36.5 \pm 1.8$ IU/L; TP: $263 \pm 13.0$ IU/L), CPK (TRP: 90.5 $\pm 3.8 \mathrm{IU} / \mathrm{L} ; \mathrm{TP}: 198 \pm 10.5 \mathrm{IU} / \mathrm{L})$ and $\mathrm{LDH}$ (TRP: $506 \pm 12.5 \mathrm{IU} / \mathrm{L}$; TP: $618 \pm 21 \mathrm{IU} / \mathrm{L}$ ) in the animals suffering from traumatic reticuloperitonitis and traumatic pericarditis as compared to the healthy control. In traumatic pericarditis there was a significant increase in the serum activities of AST $(88.32 \pm 10.81$ IU/L) with significant hyperproteinaemia $(121.2 \pm 9.3 \mathrm{~g} / \mathrm{L})$, hypoalbuminemia $(35.8 \pm$ $6.6 \mathrm{~g} / \mathrm{L})$ and hyperglobinamia $(75.5 \pm 8.2 \mathrm{~g} / \mathrm{L})$ as reported by Khalphallah et al. (2017). Marginal hyperproteinaemia in FBS affected animals in the present study could be due to sub-acute to chronic response to inflammation (Dubensky and White, 1983). The sequestration of protein in the extravascular spaces as an inflammatory response or due to malabsorption and malnutrition may lead to hypoalbuminemia which causes a change in the albumin and globulin ratio leading to hyperglobinamia. Hyperglobinamia in cattle suffering from TRP is a common observation (Hirvonen and Pyorala, 1998). The increase in the liver values of AST, ALT and LDH may suggest severe tissue destruction and muscle damage or secondary hepatic damage due to the foreign body. Increase in the $\mathrm{LDH}$ is mostly seen when there is injury to liver, skeletal muscle, cardiac muscle and kidney, is suggestive of damage by foreign body. Increase in serum CPK level, generally suggestive of cardiac and skeletal muscle affection (Ghanem, 2010).

The overall incidence of foreign body syndrome in the present study was 49.31\%.The common clinical signs included inappetence, change in the heart sound, dyspnoea, coughing, reduced rumination, jugular pulsation, intermittent pain symptoms, arched back, abducted elbows, change in posture and gait and rumen was normal to 
distended and in some cases it was impacted.The animals with TRP showed significant drop in the milk yield and was a reason for heavy economic losses.There was increase in $\mathrm{HR}, \mathrm{RR}$ and reduction in rumen motility in the affected cases. There was Nonsignificant leucocytosis with significant neutrophilia and lymphocytopenia in FBS affected cases. Non-significant hyperproteinaemia, hypoalbuminemia with significant hyperglobulinemia while levels of serum AST, ALT, CPK and LDH were significantly increased in FBS affected animals.

\section{References}

Abdelaal, A.M., andFloeck, M. 2015. Clinical and Sonographical Findings in Buffaloes (Bubalusbubalis) with Traumatic Reticuloperitonitis. VETERINARSKI ARHIV, 85(1): 1-9.

Abdelaal, A.M., and EL-Maghawry, S. 2014. Selected Studies on Foreign body Impaction in Goats with Special Reference to Ultrasonography, 7(7): 522-527.

Abdelaal, A.M., M. Floeck, S. El Maghawry and Baumgartner, W. 2009. Clinical andUltrasonographic Differences Between Cattle and Buffaloes with Various Sequelae of Traumatic Reticuloperitonitis. Veterinaria Medecinia, 54(9): 399-406.

Abouelnasr, K.S., E. Mosbah, G.I. Karrouf andZaghloul, A.E. 2012. Comparative Ultrasonographic Findings of Traumatic Reticulitis, Perireticular Abscess and Diaphragmatic Hernia in Buffalo (Bubalus bubalis). Journal of American Science, 8(8): 590-595.

Abu-Seida, A.M. and Al-Abbadi, O.S. 2015. Studies on Sharp Foreign Body Syndrome in Iraqi Buffaloes and its Impact on Milk Production. Asian Journal of Animal Sciences, 9(3): 128-
133.

Aiello, S.E., M.A. Moses, D.G. Allen, P.D. Constable, A. Dart, P.R. Davies, K.E. Quesenberry, P.T. Reeves and Sharma, J.M. $2016 . \quad$ Traumatic Reticuloperitonitis, The Merck Veterinary Manual: 11th edi. Merck \& Co., INC. KENILWORTH, NJ, USA, pp. 230-233.

Akraiem, A. and Abd Al-Galil,A.S.A. 2016 Rumen Impaction in Cattle due to Plastic Materials. Journal of Veterinary Medical Research, 23(1): 65-70.

Athar, H., J. Mohindroo, K. Singh, A. Kumar and Randhawa, C.S. 2010. Clinical, Hematobiochemical, Radiographic and Ultrasonographic Features of Traumatic Reticuloperitonitis in Bovines. Indian Journal of Animal Sciences, 80(7): 608612.

Bakhiet, A.B. 2008. Studies on the Rumen Pathology of Sudanese Desert Sheep in Slaughter House. Sci. RES. Essays, 3(7): 294-298.

Braun, U., B. Lejeune, G. Schweizer, M. Puorger and Ehrensperger, F. 2007. Clinical Findings in 28 cattle with Traumatic Pericarditis. Vet Record, 161(16): 558-563.

Braun, U., S. Warislohner, P. Torgerson, K. Nuss and Gerspach, C. 2018. Clinical and Laboratory Findings in 503 Cattle with Traumatic reticuloperitonitis. BMC Veterinary Research, 14: 66.

Dubensky, R.A and White,M.E.1983. The Sensitivity, Specificity and Predictive Value of Total Plasma Protein in the Diagnosis of Traumatic Reticuloperitonitis. Canadian Journal of Comparative Medicine 7: 241-244.

El esawy, E. E., M. S. Adel and. Ismail, S. F. 2015.Ultasonographic Diagnosis and Clinical Evaluation of Foreign Body Complications in the Compound Stomach of Cattle and Buffalo. Journal of Advanced Veterinary Research, 5(3): 
109-120.

Ghanem, M. M. 2010. A Comparative Study on Traumatic Reticuloperitonitis and Traumatic Pericarditis in Egyptian Cattle. Turk. J. Anima. Sci., 34(2): 143153.

Ghurashi, M.A., H.I. Seri, A.H. Bakheit and Ashwag, E.A. 2009. Effect of Surgical Removal of Foreign Body from Goat's Rumem with Special Referance to Prevalence of Foreign Body in Goats in Southern Darfur. AJBAS, 3(2): 664-668.

Guard, C. 2002. Traumatic Reticuloperitonitis (Hardware; Traumatic Reticulitis; TRP). In: Large Animal Internal Medicine. 3rd edn., Smith B P Mosby Inc., St. Louis, Missouri, pp. 747-753.

Hirvonen, J. and Pyorala, S. 1998. Acute Phase Protein in Dairy Cows with Surgically Treated Abdominal Disorders. Veterinary Journal 155: 5361

Hussain, T., A. Kumar and Bansal, B.K. 2018.Ferroscopy for Detection of Metallic Foreign Body in Traumatic Pericarditis and Pleural Effusions in Cattle and Buffaloes. Journal of Entomology and Zoology Studies, 6(1): 23-26.

Igbokwe, I.O., M. Y. Kolo and Egwu, G.O. 2003. Rumen Impaction in Sheep with Indigestible Foreign Body in the Semiarid region of Nigeria. Small Rum Res., 49: 141-147.

Khalphallah, A., E. Elmeligy, H. K. Elsayed, B. A. Abedellah, D. Salman, A. A. Allethie and Bayoumi, S.A. 2017. Ultrasonography as a Diagnostic Tool in Egyptian buffaloes (Bubalus bubalis) with Traumatic Pericarditis. International Journal of Veterinary Science and Medicine, 5: 159-167.

Khalphallah, A., E. Elmeligy, H. K. Elsayed, S. F. El-Hawari and Elrashidy, M. H. 2016. Diagnostic Significance of Ultrasonography in Complicated
Traumatic Reticuloperitonitis in Egyptian Buffaloes (Bubalus bubalis). Asian Journal of Animal and Veterinary Advances, 11: 319-330.

Makhdoomi, S. M., V. Sangwan andKumar,A. 2018. Radiographic Prediction of Metallic Foreign Body Penetration in the Reticulum of Cows and Buffaloes. Veterinary World, 11(4): 488-496.

Mohamed, T.2010. Clinicopathological and Ultrasonographic Findings in 40 Water Buffaloes (Bubalusbubalis) with Traumatic Pericarditis. Veterinary Record, 167: 819-824.

Nasr -Eldin, M. A. and Abdel-Hakiem,M. A. 2013. Clinical and Diagnostic Methods for Evaluation of Sharp Foreign Body Syndrome in Buffaloes. Veterinary World, 6(9): 586-591.

Otsyina, H. R., J. Nguhiu-Mwangi, E. G. M. Mogoa, P. G. Mbuthia and Ogara,W. O.2015. Prevalence of Indigestible Rumen Foreign Bodies in Sheep and Goats at Dagoretti and Kiserian Abattoirs, Kenya. Inter J Vet Sci, 4(2): 75-80.

Peighambarzadeh, S. Z. and Tavana, M. 2014. Diagnosis of Traumatic Reticuloperitonitis. Adv. Environ. Biol., 8(6): 2875-2878.

Rajput, P. K., P. V. Parikh, J. J. Parmar, T. A. Mehta and Patil, D.B. 2018. Studies on foreign Body Syndrome in Bovines of Anand District of Gujarat. Indian J. Anim. Res., 52(5): 744-749.

Sasikala, K., G. Vijayakumar, S. Sivaraman and Balasubramaniam, G.A. 2018. Clinico-Pathological Studies on Traumatic Reticuloperitonitis in Cattle A Review of 110 Cases. International Journal of Livestock Research, 8(12): 150-159.

Sharma, A. K., P. S. Dhaliwal and Randhawa, C.S. 2015. Epidemiological Studies on Forestomach Disorders in Cattle and 
Buffaloes. Veterinary World 8(9): 1063 1067.

Singh, R., A. Kumar, S. Kumar and Potliya, S. 2015. Study on Hematobiochemical, Rumen and Peritoneal Fluid Profile in Buffaloes suffering from Foreign Body Syndrome. Haryana Vet., 54(2): 103108.

Singh, S.V., K.P. Singh, J.P. Singh, D.D. Singh and Singh,H.N. 2008. Diagnosing Foreign Body in Reticulum: An Overview. Intas Polivet, 9: 127-131.
Vanitha, V., A.P. Nambi, B. Gowri and Kavitha, S. 2010. Rumen Impaction in Cattle with Indigestible Foreign Bodies in Chennai. Tamilnadu J. Veterinary and Animal Sciences, 6(3): 138-140.

Weiser, G, M.A. Thrall, G. Weise, R.W. Allison and Campbell, T.W. 2012. Interpretation of Leukocyte Response in Disease. Veterinary haematology and clinical chemistry. Ames: WileyBlackwell. pp. 127-139.

\section{How to cite this article:}

Lakhpati, A. S., B. N. Ambore, G. D. Wankhede, V. R. Patodkar, S. U. Digraskar, R. V. Suryawanshi and Mali, A. B. 2019. Foreign Body Syndrome in Cattle: An Incidence and Clinico-Haemato-Biochemical Changes. Int.J.Curr.Microbiol.App.Sci. 8(09): 783-798. doi: https://doi.org/10.20546/ijcmas.2019.809.094 